\title{
O grupo de Trabalho e a Eficiência Individual
}

\author{
T'omás de Vilanova Monteiro Lopes
}

\author{
A EFICIÊNCIA COMO RESULTANTE DE DETERMINADO TIPO \\ DE CONDUTA
}

\section{$\mathrm{E}$}

StAmos quase todos inclinados, numa certa medida, a conceber a eficiência mais como um ideal do que como simples aspecto da realidade. Por isso mesmo a conhecemos tão mal e, muitas vêzes, não conseguimos sequer distinguir as diferentes formas søb as quais ela se apresenta.

A conceituação da eficiência revela suas dificuldades mesmo quando pretendemos alcançá-la, partindo do elemento gramatical. A Enciclopédia Britânica (ed. de 1951) não registra o vocábulo eficiência. A Enciclopédia Americana (ed. de 1940) o registra como palavra moderna, sem correspondente em várias linguas (francês, italiano, russo, sueco, alemão) e que serve para definir a relação industrial entre aquilo que é e o que devia ser, entre o resultado obtido e o seu padrão.

O conceito de eficiência é, em verdade, um conceito complexo. Exprimi-lo como a relação positiva entre aquilo que se espera e o que se obtém de uma pessoa (ou coisa) importa em transformar o êxito na medida da eficiência. Mas, por acaso, não se pode ter êxito sem ser eficiente? ou ser eficiente sem ter êxito?

Basta abrirmos os olhos sôbre o que se passa em tôrno de nós para compreendermos que eficiência e êxito nem sempre são o verso e o anverso da mesma medalha. Tomemos dois pequenos exemplos: o do jogador que vê o seu número premiado no giro da roleta; e o do médico que depois de aplicar, dentro da mais rigorosa técnica, os melhores recursos da ciência indicados para o caso não consegue salvar o seu doente. Onde estaria a eficiência? Com o jogador a quem a sorte sorriu? ou com o médico que não teve êxito em seus esforços?

$\mathrm{O}$ que parece existir de fundamental na eficiência é o esfôrço voluntário e consciente, no sentido de alcançar determinado objetivo, mediante a correta utilização dos meios adequados para tal. Ser eficiente implica, portanto, em possuir competência e em 
utilizar, consciente e voluntàriamente, essa competência para atingir um dado fim. O acaso pode produzir o êxito, mas não produz a eficiência, pois que esta, ao nosso ver, é o produto de um tipo de conduta que se constitui pela conjugação da capacidade e da vontade, orientadas ambas para o objetivo colimado. A capacidade (elemento intelectual) fornece o conhecimento e a técnica; a vontade (elemento afetivo) alimenta o interêsse e a dedicação ao trabalho, os quais, por sua vez, levam o indivíduo a descobrir as melhores soluções para os problemas com os quais se defronta na prática. Nem a capacidade nem a vontade são elementos transitórios. Uma e outra se traduzem num esfôrço continuado, numa organização de propósito e de meios. A eficiência que delas resulta é um estado permanente, que subsiste enquanto o conjunto de circunstâncias sob o qual o indivíduo atua se mantém inalterado. $O$ individuo eficiente não o é, apenas, quando o acaso o permite. A eficiência, longe de ser um efeito momentâneo, constitui uma qualidade constante, a qual, embora sujeita a flutuações, conserva através destas sua continuidade essencial.

Como resultante de um determinado tipo de conduta, a eficiência pode, inclusive, ser prevista pelo mecanismo das relações entre causa e efeito. Isso, que assume especial importância do ponto-de-vista da organização do trabalho, uma vez que permite tomar a eficiência como um dado de planejamento, nem sempre ocorre com o êxito. Este, em determinados casos, é, realmente, um reflexo da eficiência e, como tal, pode ser previsto; mas em grande número de outros é incerto, porque depende do acaso, de influência ocasionais ou de fatôres inteiramente fora do contrôle de que se pode lançar mão na execução do trabalho.

Para que o êxito seja um reflexo da eficiência e, conseqüentemente, um instrumento para sua medida, duas condições, pelo menos, são necessárias:

a) que a atividade a que êle diz respeito seja daquelas nas quais o sucesso ou insucesso depende de fatôres totalmente subordinados à atuação de quem a exerce; $e$

b) que êle seja constante e não deixe de se manifestar enquanto o conjunto de circunstâncias sob as quais a atividades é exercida permanẹça inalterado.

A primeira condição exclui o êxito aleatório; a segunda, o êxito episódico; e as duas juntas fazem o verdadeiro êxito, o único que pode ser tomado como medida legítima da eficiência. Mas, como é fácil de observar, as aludidas condições exprimem aquêle tipo de conduta sem o qual a eficiência não existe. Com efeito, se o individuo que exerce a atividade não dispuser dos conhecimentos e das aptidôes indispensáveis, sua atuação será 
falha, não lhe permitindo exercer o efetivo contrôle dos fatôres dos quais o êxito depende, nem manter êsse contrôle enquanto êle fôr necessário. Assim, mesmo naqueles casos em que o êxito e a eficiência se identificam, o que há de fundamental nesta última, como já dissemos antes, é o esfôrço voluntário e consciente, no sentido de alcançar determinado objetivo mediante a correta utilização dos recursos adequados para tal. $O$ indivíduo não será eficiente por obter êxito; ao contrário, êle obterá êxito por ser eficiente.

\section{EFICIÊNCIA E INTEGRAÇÃO AO GRUPO DE TRABALHO}

Mas quando o individuo adota o tipo de conduta que descrevemos de início como característica fundamental da eficiência, é porque se acha integrado ao grupo de trabalho a que pertence. Numa situação de desajustamento não agiria êle, no desempenho de suas funções, com o mesmo senso de responsabilidade, o mesmo espírito de cooperação e o mesmo ânimo de servir da melhor forma possivel os objetivos do seu grupo de trabalho. Sua conduta é típica de quem aceitou o grupo, de quem se integrou e não, simplesmente, se justapôs.

O trabalhador verdadeiramente eficiente é sempre um individuo integrado ao seu grupo de trabalho. Não se pode ser eficiente senão dentro dessa condição; mas se pode ter êxito fora dela. Desde que a eficiência é um valor social, ou, em melhores têrmos, desde que ela evidencia a realização dos objetivos do grupo, seria ilógico admiti-la no individuo desajustado a êsse mesmo grupo. O êxito é algo que pode ser alcançado até mesmo contra os objetivos do grupo; a eficiência não. A história da humanidade, sobretudo no que respeita à conquista do poder e da riqueza, está cheia de exemplos de pessoas que realizaram suas ambições, que tiveram êxito à custa do sacrifício e até mesmo da destruição dos respectivos grupos.

Quando nos referimos à eficiência no trabalho, tomamos a atuação de cada individuo em função do grupo a que êle pertence, uma vez que as relações entre o individuo e o grupo consistem, essencialmente, em dar e receber. $O$ individuo é eficiente na medida em que recebe e dá, na medida em que através de suas atividades realiza os objetivos do grupo a que se acha filiado. A eficiência do indivíduo não pode, portanto, ser alcançada em detrimento do grupo, pois que deve servi-lo e não prejudicá-lo.

O CONDICIONAMENTO DA EFICIÊNCIA INDIVIDUAL PELO GRUPO DE TRABALHO

Não é regra geral, entretanto, a inteira subordinação dos fatôres de êxito à atuação de quem exerce uma atividade qual. 
quer. O sistema atual de organização do trabalho faz com que os diferentes tipos de atividade se complementem mùtuamente e dependam uns dos outros. O reativo que o químico utiliza em seu laboratório, o aço com que o operário torneia suas engrenagens ou o tecido com o qual o alfaiate confecciona suas peças são o produto de um sem-número de operações das quais participaram muitos outros indivíduos. Todos êstes são também responsáveis pelo sucesso ou insucesso do quimico, do torneiro, do alfaiate. Quem dirá que o reativo, por um defeito de composição, não irá produzir fenômenos diferentes daqueles que seria licito esperar? Não poderá, porventura, a qualidade do aço provocar a fratura das engrenagens em circunstâncias que levariam a supor que o torneiro não soube executar o seu trabalho com proficiência? Haverá, acaso, algum absurdo em se admitir que a má qualidade do tecido poderá obstar que o alfaiate dê à sua obra um acabamento esmerado?

Quando passamos ao campo mais vasto da produção em massa, vemos que a dependência do individuo em relação ao grupo de trabalho ainda mais se acentua. PETER DRUCKER observa a respeito que:

"Na organização do trabalho, segundo o principio da produção em massa, a unidade de trabalho individual não é o produto, mas uma única operação ou único movimento. O produto é o resultado de milhares de outras operações semelhantes, cada uma executada por um único operador. Nenhum operador seria capaz de fazer o produto por mais tempo que dedicasse à tarefa". ("A Nova Sociedade", trad. de Esmerino MAGAlHães, Editora Ipanema Ltda. - Rio, 1957).

Não é, pois, apenas o fator azar, componente natural de certos tipos de trabalho, e influência a que outros estão sujeitos em maior ou menor escala, que impede o inteiro contrôle dos fatôres de que depende o sucesso ou insucesso na execução do trabalho. O próprio sistema atual de organização da produção exerce o mesmo efeito, e de maneira geral e constante. Mas o sistema de organização da produção foi instituido pelo grupo; é êle próprio um dos muitos instrumentos de que se vale o grupo para condicionar o indivíduo a um determinado tipo de conduta.

Assim, ao lado da atuação particular de cada um dos componentes do grupo de trabalho, a qual se pode manifestar sob as diferentes formas de cooperação, competição e conflito, a que a convivência dá origem, há, ainda, a atuação do grupo como instituição integrada e autônoma, impondo a cada individuo um 
conjunto de objetivos e de meios: o sistema de organização da produção, fora do qual não se pode conceber a eficiência como dado objetivo.

Cada membro do grupo, para desempenhar, eficientemente o seu papel, terá, antes de mais nada, de apreender êsse sistema de organização da produção e de a êle ajustar-se.

O processo de apreensão e ajustamento a que nos estamos referindo é uma responsabilidade conjunta do grupo social e do indivíduo. Um e outro se devem, mùtuamente, uma atitude de cooperação. O grupo de trabalho cumpre a sua por diversas maneiras, e destas há duas que se prestam a um exemplo suficientemente ilustrativo: - a formação profissional e o treinamento, por isso que através de ambas e com o auxilio dos meios de comunicação apropriados, o indivíduo é moldado para o tipo de conduta, para a forma específica de convivência, que o grupo adotou como conveniente aos seus objetivos.

A experiência e as técnicas de trabalho do grupo, ao mesmo tempo que se transmitem ao indivíduo, dão a êste último uma diretriz e um sentido de integração. O processo não é apenas de aquisição de conhecimentos, mas também de formação e fixação de hábitos e atitudes.

Tudo isso, porém, redundaria em pura perda sem a cooperação do indivíduo para com o grupo, eis que tal cooperação significa, principalmente, receptividade e aproveitamento. Numa linguagem um pouco mais simbólica: o indivíduo precisa saber receber aquilo que o grupo the dá. A formação profissional e o treinamento - para nos cingirmos ao exemplo que escolhemos estariam votados ao fracasso se os indivíduos aos quais se destinam não lhes respondessem com uma atitude positiva, de cooperação.

O grupo não sòmente estabelece, em função de seus objetivos, o que se pode considerar como eficiência individual; não apenas oferece ao individuo, através da organização dos seus meios, a condição de adaptação àqueles objetivos e aos processos de transmiti-los sob as formas mais convenientes; além disso fixa êle próprio os critérios para a aferição da eficiência individual. 